\title{
Excision of Needles Embedded in the Lung and Chest Wall
}

\author{
Enosh Siraj, Mahmoud Loubani, Syed Qadri, Azar Hussain* \\ Department of Cardiothoracic Surgery, Castle Hill Hospital, Castle Road, Cottingham, HU16 5JQ, United \\ Kingdom
}

*Corresponding Author: Azar Hussain, Department of Cardiothoracic Surgery, Castle Hill Hospital, Castle Road, Cottingham, HU16 5JQ, United Kingdom.

Summary

A 25-year-old male was referred to cardiothoracic surgical unit for emergency removal of sewing needles in his chest. The injuries were self-inflicted. CT scan revealed multiple needles in patient's chest, puncturing the lung and pleura creating a pneumothorax.

Two needles were removed by emergency thoracotomy while remaining needles, which were embedded in the subcutaneous tissue were not removed. Patient did not have any post-operative complications and was booked in for a follow up for 6 weeks' time.

\section{BACKGROUND}

While penetrating chest trauma is less common than blunt it needs to be dealt with quickly and carefully [1]. Penetrating chest trauma can be life threatening with some patients dying even before they arrive at the hospital [2]. Foreign bodies such as needles in the chest have been reported in several different studies for different reasons. Most common causes being self-harm [3], acupuncture [4], child abuse [5], drug abuse [6] or accidental [7]. While most cases have similar presentation, such as chest pain and entry wounds, some cases go unnoticed for long periods of time [8].

While most cases can be managed conservatively, surgery is needed in others [1]. Foreign bodies, like needles, can often migrate, puncturing organs or major vessels, causing a pneumothorax or major bleeding $[9,10]$. If in the thorax, needles can perforate the lung, major pulmonary/systemic vessels or the heart that might be life threatening [10].

This report covers a patient suffering from a pneumothorax as a result of needles in the chest wall and lung. An emergency thoracotomy was performed since one of the needles had penetrated the lung and was close to the pulmonary artery.

\section{Case Presentation}

A 25-year-old male presented with a case of self-harm claiming to have inserted 3 sewing needles in his chest. The patient had a previous history of anxiety, depression, PTSD, as well as suicidal thoughts and attempts. The patient did not complain about the pain and puncture wounds were seen on top of the chest and air leak was observed when patient coughed. Initial Chest X Rays showed 4 needles in the right anterior chest and 2 in the left anterior chest (Figure 1). To further investigate a computed tomography (CT) scan was done (Figure 2). The CT showed one needle embedded in the left upper lobe close to the pulmonary artery (PA). Another needle was protruding through anterior chest wall into the chest cavity and would come in contact with the inflated lung (Figure 3). This had created a pneumothorax, so a chest drain was inserted, and the patient was transferred to the cardiothoracic surgical unit. 


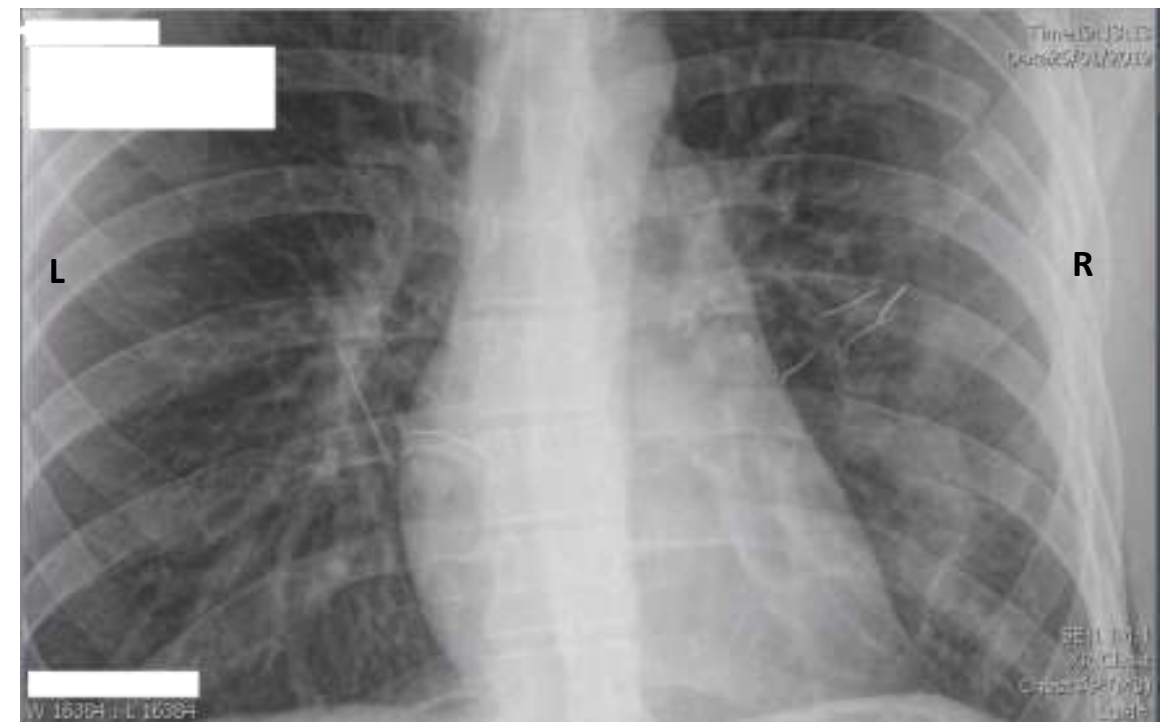

Figure 1. Patient's X-Ray shows the number of needles embedded in the anterior chest wall. Two can be seen embedded in the left anterior thorax and four were seen in the right thorax

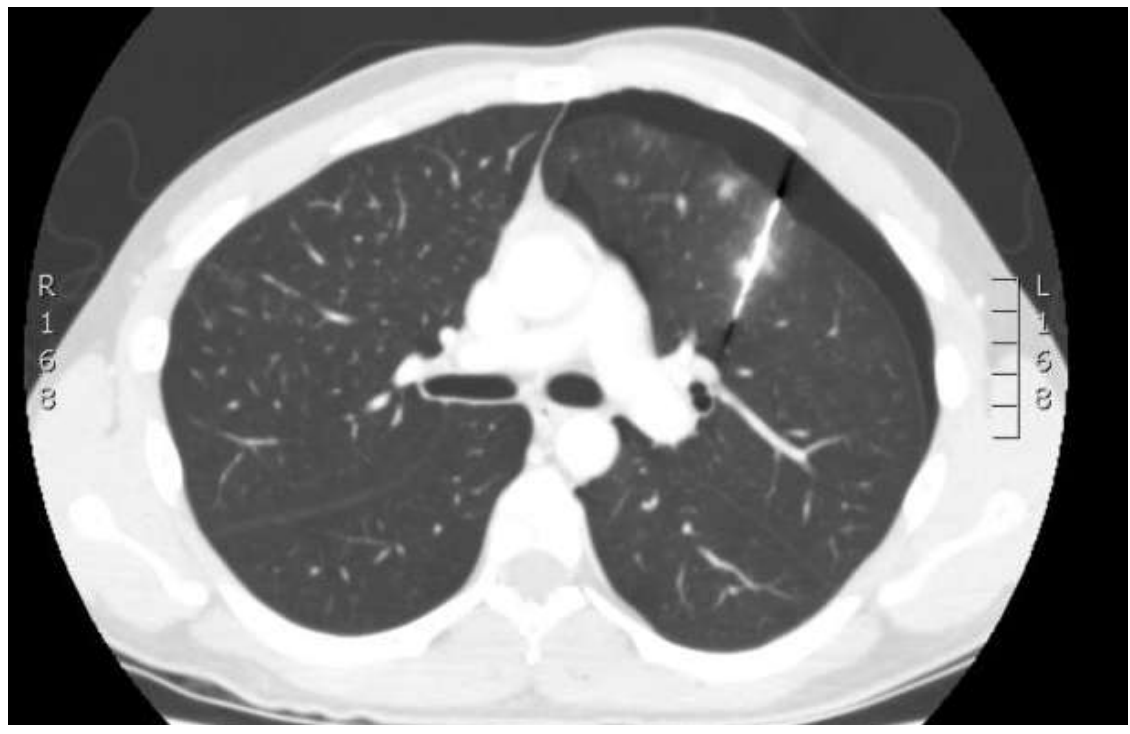

Figure 2. Further CT scan shows one of the needles embedded in the left lung close to the pulmonary artery

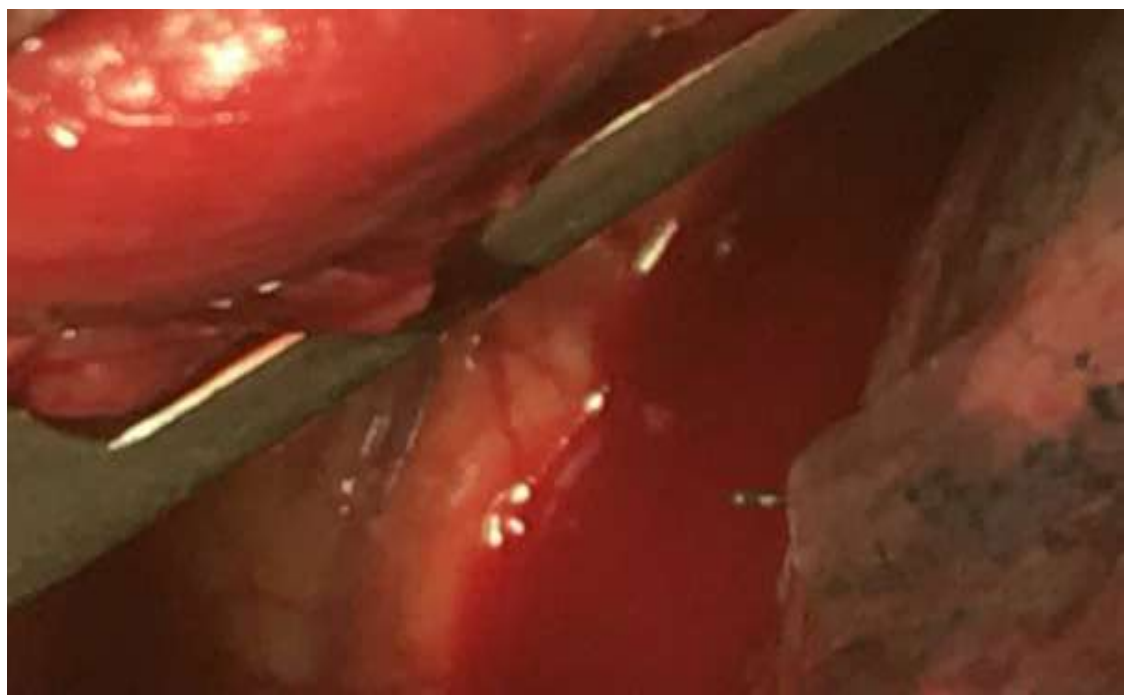

Figure 3. Needle can be seen protruding through the chest wall 
An emergency left posterolateral thoracotomy was performed to remove the two needles from the left anterior chest, the lungs were inflated during the surgery. However, the remaining needles that were embedded in the subcutaneous tissue, were not removed as they were not visible. Post-op a chest drain was inserted, and patient was kept in recovery before being transferred to the ward.

Outcome and Follow-up: He underwent chest physiotherapy to speed up recovery. There was no post-op complication, and he was discharged following chest drain removal with a follow scheduled for 6 weeks.

\section{DISCUSSION}

Similar cases have been reported where patients inserted foreign objects especially needles in their body. Agorastos et al. [3] reported a similar case, where a patient intentionally inserted a pencil into their thorax. While initially the objects remained undetected, the patient eventually developed an infection and required thoracotomy to remove object from basal lobe. The case was published by the American Journal of Psychiatry therefore did not discuss the surgical details extensively. Nonetheless, similar to our case the object was embedded in the lung tissue and to prevent further damage to the tissue and migration of the foreign object a thoracotomy was performed. While most cases use a mini-incision or videoassisted thoracoscopic surgery (VATS), emergency open thoracotomy has been recommended in penetrating thoracic trauma producing better survival rate $[11,12]$.

Another study by Weissberg and WeissbergKasav [11] reported 22 cases, where surgical intervention was needed to remove foreign objects from the thorax between 1971 and 2001. In 5 out of 22 cases multiple needles were found. In each of these cases the patients were either having a psychotic episode or were intending self-harming. Pneumothorax was observed in all cases due to damage to chest wall and pleura.

Treatment used for removal of needles and foreign bodies can vary depending on the position and nature. It has been observed that foreign objects such as needles tend to migrate away from the initial site of entry potentially entering organs and vessels. Even needles that may lie dormant in subcutaneous tissue will eventually resurface and may require surgery
[4]. Foreign objects that have stayed in the body for a prolonged period of time may cause complications. Some metallic objects will rust [5] while organic objects my decay [3] leading to infection.

VATS, pleuroscopy or mini-incision are considered the best treatment plan for certain thoracic injuries. VATS is often used in cases with pleura or chest wall damage [4] while thoracotomy is ideal for extracting long sharp objects [9]. However, when organ damage is seen such as in this case it is vital that the position of needle or foreign object should be ascertained before surgery. In our case, the needle was close to the PA. To prevent PA from being punctured a thoracotomy was performed. The lungs were inflated to prevent the needle from further migrating and puncturing PA and to improve visibility. Performing VATS would have deflated the tissue and reduced visibility of the needle embedded in the lung. In some cases the foreign body will migrate further inside the thoracic cavity and will penetrate the heart [9]. If not detected in time it can lead to complication such as infection [10] and cardiac tamponade [13]. The rate of migration seen in children is a lot faster, as reported by Schultz et al. [9], where the needles migrated from the chest wall to the heart between the CT-scan and the surgery. Therefore, penetrating thoracic trauma should be managed by multidisciplinary team involving physiotherapists, mental health professionals, thoracic and cardiac surgeons.

\section{Conclusion}

It is vital to carefully identify all the foreign bodies in the body as they can be easily missed [8]. It is important to understand their position in relation to organs and vessels. Objects in the thorax may cause structural damage leading to pneumothorax, haemothorax, bleeding or death. Patient and physicians should be mindful of the migratory nature of foreign objects when leaving in indolent objects. The nature of objects should also be kept in mind when deciding treatment options. Some objects will lead to an infection while others can remain in body without being life threatening. Removal of these objects should be done carefully to prevent further damage. In our case it was vital to keep the lungs inflated so that needle remained visible did not slide further, damaging the PA or other thoracic structures, making thoracotomy the ideal procedure. 


\section{REFERENCES}

[1] Jain A, Burns B. Penetrating Chest Trauma [Internet]. StatPearls. 2019. Available from: https://www.ncbi.nlm.nih.gov/books/NBK5354 44/

[2] Sersar SI, Albohiri KA, Abdelmohty H. Impacted thoracic foreign bodies after penetrating chest trauma. Asian Cardiovasc Thorac Ann [Internet]. 2016;24(8):782-7. Available from: https://doi.org/10.1177/ 0218492316664673

[3] Agorastos A, Huber CG, Dunker S, Wiedemann K. Reduced pain perception in schizophrenia: a case of an undetected intrathoracic pencil. Am J Psychiatry [Internet]. 2011 Aug;168(8):854-5. Available from: http://www.ncbi.nlm.nih.gov/pubmed/21813498

[4] von Riedenauer WB, Baker MK, Brewer RJ. Video-assisted thorascopic removal of migratory acupuncture needle causing pneumothorax. Chest [Internet]. 2007 Mar;131(3):899-901. Available from: http://www.ncbi.nlm.nih.gov/pubmed/17356111

[5] Deng X, Huang P, Wang J, Yi L, Liu J, Yang G. Sewing needles in the lungs of children: Two case reports. Medicine (Baltimore) [Internet]. 2019 [cited 2019 Nov 3];98(15):e15186. Available from: http://dx.doi.org/10.1097/MD.0000000000015186

[6] Al-Sahaf M, Harling L, Harrison-Phipps K, Bille A. An Unusual Case of Needle Embolus Presenting With Delayed Spontaneous Pneumothorax. Ann Thorac Surg [Internet]. 2016 Sep;102(3):e201-3. Available from: https://www.annalsthoracicsurgery.org/article/ S0003-4975(16)00096-5/fulltext

[7] Shoko T. Accidental chest penetration of glass foreign bodies in a 53 year old lady - The challengeswith video assisted thoracoscopic extraction. Int J Surg Case Rep [Internet]. 2016 [cited 2019 Nov 3];23:124-7. Available from: http://dx.doi.org/10.1016/j.ijscr.2016.03.045

[8] Apiliogullari B, Duzgun N, Kurtipek E, Esme H. Retained foreign body after chest stab wound. BMJ Case Rep [Internet]. 2014 [cited 2019 Nov 3]; Available from: http://group.bmj.com/group/rights-

licensing/permissions.

[9] Schultz JJ, Post ME, Plumley DA, O'Brien MC, DeCampli WM. Migration of a Needle From the Chest Wall Into the Right Ventricle in a 10-Year-Old Child. World J Pediatr Congenit Heart Surg [Internet]. 2016;7(6):761-4. Available from: http://www.ncbi.nlm.nih.gov/pubmed/26884448

[10] Rossi MA, Alvarenga DG, Agrizzi RS. Sewing Needle Transfixing the Posterior Wall of the Left Ventricle Causes Death. Circulation [Internet]. 1999 Feb 16;99(6):843-4. Available from: https://www.ahajournals.org/doi/10.1161/ 01.CIR.99.6.843

[11] Weissberg D, Weissberg-Kasav D. Foreign bodies in pleura and chest wall. Ann Thorac Surg [Internet]. 2008 Sep;86(3):958-61. Available from: http://www.ncbi.nlm.nih.gov/ pubmed/18721591

[12] Tan BKK, Pothiawala S, Ong MEH. Emergency thoracotomy: a review of its role in severe chest trauma. Minerva Chir [Internet]. 2013 Jun;68(3):241-50. Available from: http://www.ncbi.nlm.nih.gov/pubmed/23774089

[13] Vesna D, Tatjana A, Slobodan S, Slobodan N. Cardiac tamponade caused by migration of a swallowed sewing needle. Forensic Sci Int [Internet]. 2004 Jan 28;139(2-3):237-9. Available from: http://www.ncbi.nlm.nih.gov/ pubmed/15040923

Citation: Enosh Siraj, Mahmoud Loubani, Syed Qadri, Azar Hussain. Excision of Needles Embedded in the Lung and Chest Wall. ARC Journal of Clinical Case Reports. 2020; 6(4):14-17. DOI:https://doi.org/10.20431/2455-9806.0604004.

Copyright: (c) 2020 Authors. This is an open-access article distributed under the terms of the Creative Commons Attribution License, which permits unrestricted use, distribution, and reproduction in any medium, provided the original author and source are credited. 